(2) Open Access Full Text Article

ORIGINAL RESEARCH

\title{
Personal best times in an Olympic distance triathlon and in a marathon predict Ironman race time in recreational male triathletes
}

This article was published in the following Dove Press journal:

Open Access Journal of Sports Medicine

19 August 2011

Number of times this article has been viewed

Christoph Alexander Rüst ${ }^{\prime}$

Beat Knechtle ${ }^{1,2}$

Patrizia Knechtle ${ }^{2}$

Thomas Rosemann'

Romuald Lepers ${ }^{3}$

'Institute of General Practice and Health Services Research, University of Zurich, Zurich, Switzerland;

${ }^{2}$ Gesundheitszentrum St Gallen, St Gallen, Switzerland; ${ }^{3}$ INSERM U887, University of Burgundy, Faculty of Sport Sciences, Dijon, France
Correspondence: Beat Knechtle Facharzt FMH für Allgemeinmedizin, Gesundheitszentrum St Gallen, Vadianstrasse 26, 900 I St Gallen, Switzerland

Tel +4I 07 I 2268282

Fax +4I $07 \mid 2268272$

Email beat.knechtle@hispeed.ch
Background: The purpose of this study was to define predictor variables for recreational male Ironman triathletes, using age and basic measurements of anthropometry, training, and previous performance to establish an equation for the prediction of an Ironman race time for future recreational male Ironman triathletes.

Methods: Age and anthropometry, training, and previous experience variables were related to Ironman race time using bivariate and multivariate analysis.

Results: A total of 184 recreational male triathletes, of mean age $40.9 \pm 8.4$ years, height $1.80 \pm 0.06 \mathrm{~m}$, and weight $76.3 \pm 8.4 \mathrm{~kg}$ completed the Ironman within $691 \pm 83$ minutes. They spent $13.9 \pm 5.0$ hours per week in training, covering $6.3 \pm 3.1 \mathrm{~km}$ of swimming, $194.4 \pm 76.6 \mathrm{~km}$ of cycling, and $45.0 \pm 15.9 \mathrm{~km}$ of running. In total, 149 triathletes had completed at least one marathon, and 150 athletes had finished at least one Olympic distance triathlon. They had a personal best time of 130.4 \pm 44.2 minutes in an Olympic distance triathlon and of $193.9 \pm 31.9$ minutes in marathon running. In total, 126 finishers had completed both an Olympic distance triathlon and a marathon. After multivariate analysis, both a personal best time in a marathon $(P<0.0001)$ and in an Olympic distance triathlon $(P<0.0001)$ were the best variables related to Ironman race time. Ironman race time (minutes) might be partially predicted by the following equation: $\left(r^{2}=0.65\right.$, standard error of estimate $\left.=56.8\right)=152.1+1.332 \times($ personal best time in a marathon, minutes $)+1.964 \times$ (personal best time in an Olympic distance triathlon, minutes).

Conclusion: These results suggest that, in contrast with anthropometric and training characteristics, both the personal best time in an Olympic distance triathlon and in a marathon predict Ironman race time in recreational male Ironman triathletes.

Keywords: body fat, swimming, cycling, running, triathlon

\section{Introduction}

The Ironman triathlon is the most popular long-distance triathlon. Since the first event, held in 1978 in Hawaii, tens of thousands of triathletes compete in Ironman races every year to qualify for the Ironman World Championship in Hawaii (http:// ironman.com/worldchampionship), where more than 1700 triathletes start per year. ${ }^{1,2}$ Competing and finishing an Ironman triathlon requires an athlete to train and race in three different disciplines where, apart from the physiological variables, anthropometric characteristics, training, and previous experience might also be associated with race performance.

Several studies have been undertaken to determine predictor variables for an Ironman race time. For male Ironman triathletes, percent body fat, ${ }^{3,4}$ sum of upper body skinfold thicknesses, ${ }^{5}$ personal best time in an Olympic distance triathlon ${ }^{6,7}$ and 
personal best marathon time ${ }^{7}$ were related to Ironman race time. Previous best performances in an Olympic distance triathlon coupled with weekly cycling distances and longest training ride could partially predict overall performance. ${ }^{6}$ Most of the Ironman triathletes have finished an Olympic distance triathlon prior to starting in an Ironman triathlon. ${ }^{6}$

The aim of this study was to investigate in Ironman Switzerland, a qualifier for Ironman Hawaii, which of the basic variables of age, anthropometric characteristics, training, and previous race experience was related to an Ironman race time. It was hypothesized that lower body fat, a higher cycling training volume, and a faster personal best time in both an Olympic distance triathlon and a marathon would be correlated with a faster Ironman race time. In addition, we intended to create an equation to predict an Ironman race time for future novice Ironman triathletes based upon basic measurements that any recreational athlete could determine for himself, without the need for highly sophisticated equipment. An equation to predict Ironman race time might help future Ironman triathletes to prepare better for a race and coaches to improve their instructions for athletes. Athletes, coaches, and dieticians may find this information valuable, especially when planning for an athlete's first event. It is also important from a race nutrition perspective to know approximately how fast an athlete may complete the Ironman.

\section{Materials and methods Subjects}

All the male triathletes at Ironman Switzerland were informed of the planned study via an electronic newsletter sent by the organizer 3 months before the start of the race, plus separate information shown on the race website. The study was approved by the institutional review board for use of human subjects at the Canton of St Gallen, Switzerland. The athletes were informed of the experimental procedures and gave their informed written consent. A total of 211 recreational, nonprofessional male triathletes volunteered to take part in the investigation in the years 2007-2010. A recreational athlete was defined as an athlete who was not earning his livelihood with prize money from races and financial support by sponsors. A total of 184 participants aged $40.9 \pm 8.4$ years, weight $76.3 \pm 8.4 \mathrm{~kg}$, height $1.80 \pm 0.06 \mathrm{~m}$, and body mass index $23.5 \pm 2.0 \mathrm{~kg} / \mathrm{m}^{2}$ attended for prerace measurements and completed Ironman Switzerland within the time limit of 16 hours.

\section{Design}

A cross-sectional, observational field study was performed at Ironman Switzerland (http://www.ironman.ch/). In order to increase the sample size, data from the 2007-2010 races were collected. In Ironman Switzerland, athletes had to swim two laps in Lake Zurich to cover the $3.8 \mathrm{~km}$ and then had to cycle two laps of $90 \mathrm{~km}$ each, followed by running four laps of $10.5 \mathrm{~km}$ each. In the cycling section, the highest point to climb from Zurich ( $400 \mathrm{~m}$ above sea level) was the "Forch" (700 $\mathrm{m}$ above sea level), while the running course was completely flat in the city of Zurich.

\section{Measurements and calculations}

Upon entry to the study 3 months before the start of Ironman Switzerland, the subjects were asked to record each training unit, showing duration (minutes) and distance $(\mathrm{km})$ for all three disciplines. The investigator provided a file in which the subjects could insert each training unit with distance, duration, and speed, expressed in $\mathrm{km} / \mathrm{hour}$. The investigator calculated mean weekly hours, mean weekly kilometers, and mean speed per discipline during training in the prerace preparation. The subjects also reported their personal best times in an Olympic distance triathlon, as well as in a marathon, where personal best time was defined as the best time ever achieved in their career on that distance, independent of the race course and environmental factors.

The afternoon before the start of the race, body mass, height, circumferences, and length of limbs as well as thicknesses of skinfolds were measured. The lengths and circumferences of the limbs and all skinfold thicknesses were measured on the right side of the body. With these data, body mass index and percent body fat were calculated using an anthropometric method. Body mass was measured using a commercial scale (Beurer BF 15, Beurer, Ulm, Germany) to the nearest $0.1 \mathrm{~kg}$. Height was determined using a stadiometer to the nearest $1.0 \mathrm{~cm}$. The circumferences and lengths of limbs were measured using a nonelastic tape measure (KaWe CE, Kirchner und Welhelm, Germany) to the nearest $0.1 \mathrm{~cm}$. The length of the arm was measured from the acromion to the tip of the third finger, and the length of the leg from the trochanter major to the malleolus lateralis. The circumference of the upper arm was measured at the mid upper arm, the circumference of the thigh at mid thigh, and the circumference of the calf at mid calf. All skinfold data were obtained using a skinfold caliper (GPM-Hautfaltenmessgerät, Siber and Hegner, Zurich, Switzerland) and recorded to the nearest $0.2 \mathrm{~mm}$. The skinfold measurements were taken once for all eight skinfolds of the chest, mid axilla, triceps, subscapular region, abdomen, suprailiac region, front thigh, and medial calf. This procedure was repeated twice more by the same investigator, and the mean of three measurements was then 
used for the analyses. The timing of the taking of the skinfold measurements was standardized to ensure reliability. According to Becque et al, readings are performed 4 seconds after applying the caliper. ${ }^{8}$ Percent body fat was estimated using the anthropometric formula according to Ball et al, with percent body fat $=0.465+0.180 \times(\Sigma 7 \mathrm{SF})-0.0002406 \times(\Sigma 7 \mathrm{SF})^{2}+$ $0.0661 \times($ age $)$, where $\Sigma 7 \mathrm{SF}=$ sum of skinfold thickness of the chest, mid axilla, triceps, subscapular region, abdomen, suprailiac region, and thigh. ${ }^{9}$

One trained investigator took all the skinfold measurements because intertester variability is a major source of error in those measurements. An intratester reliability check was conducted on 27 male athletes prior to testing. The intraclass correlation within the two judges was excellent for all anatomical measurement sites and various summary measurements of skinfold thicknesses (intraclass correlation $>0.9$ ). Agreement tended to be higher within measurers than between measurers but still reached excellent reliability (intraclass correlation $>0.9$ ) for the summary measurements of skinfold thicknesses. ${ }^{10}$ The formula to estimate body fat in males was evaluated using 160 men aged 18-62 years and crossvalidated using dual energy X-ray absorptiometry. The mean differences between dual energy X-ray absorptiometry percent body fat and calculated percent body fat ranged from $3.0 \%$ to $3.2 \%$. Significant $(P<0.01)$ and high $(r>0.9)$ correlations existed between the anthropometric prediction equations and dual energy X-ray absorptiometry. ${ }^{9}$

\section{Statistical analysis}

Data were analyzed using SPSS software (v 15; SPSS Inc, Chicago, IL). Data were checked for distribution of normality, and normally distributed data are presented as means \pm standard deviation. In a first step, the relationship between Ironman race time as the dependent variable and the variables of age, anthropometry, training, and previous experience was investigated using a bivariate Pearson correlation analysis in order to reduce the number of variables for a multiple linear regression analysis. In a second step, all significant variables after bivariate analysis were entered into a multiple linear regression analysis (stepwise, forward selection, $P$ of $F$ for inclusion $<0.05, P$ of $F$ for exclusion $>0.1$ ). Multicollinearity between the predictor variables was excluded with $r>0.9$. Significant variables were used to create an equation to predict Ironman race time. A power calculation was performed according to Gatsonis and Sampson. ${ }^{11}$ To achieve a power of $80 \%$ (two-sided type I error of 5\%) to detect a minimal association between race time and anthropometric characteristics of $20 \%$ (ie, coefficient of determination $r^{2}=0.2$ ), a sample of 40 participants was required. Effective race time was compared with predicted race time using a paired $t$-test. An alpha level of 0.05 was used to indicate significance for all statistical tests.

\section{Results}

A total of 184 subjects completed the Ironman Switzerland within $691 \pm 83$ minutes, and the split times were $76 \pm 12$ minutes for swimming, $349 \pm 39$ minutes for cycling, and $257 \pm 41 \mathrm{~min}-$ utes for running, respectively. The swimming speed of $3.0 \pm 0.4 \mathrm{~km} /$ hour and the cycling speed of $31.3 \pm 3.3 \mathrm{~km} /$ hour during the race were significantly faster than the speeds achieved in these disciplines during training $(P<0.001)$. For running, the speed of $10.1 \pm 1.5 \mathrm{~km} /$ hour during the race was significantly slower compared with the speed during training $(P<0.0001)$. Table 1 represents age, anthropometry, training, and previous experience, including the correlation

Table I Anthropometric characteristics, training, and race experience of the subjects and bivariate association with Ironman race time

\begin{tabular}{|c|c|c|c|}
\hline Measures & Result & Pearson $r$ & $P$ value \\
\hline Age (years) & $40.9(8.4)$ & 0.32 & $<0.000$ I \\
\hline Body height (m) & $1.80(0.06)$ & 0.02 & \\
\hline Body mass (kg) & $76.3(8.4)$ & 0.25 & 0.0005 \\
\hline Body mass index $\left(\mathrm{kg} / \mathrm{m}^{2}\right)$ & $23.5(2.0)$ & 0.32 & $<0.0001$ \\
\hline Length of leg (cm) & $86.2(4.8)$ & -0.04 & \\
\hline Length of arm (cm) & $80.7(4.2)$ & 0.04 & \\
\hline $\begin{array}{l}\text { Circumference of upper } \\
\operatorname{arm}(\mathrm{cm})\end{array}$ & $30.1(3.0)$ & 0.21 & 0.0035 \\
\hline Circumference of thigh $(\mathrm{cm})$ & $54.5(3.5)$ & 0.19 & 0.0090 \\
\hline Circumference of calf $(\mathrm{cm})$ & $37.1(3.3)$ & 0.17 & 0.0219 \\
\hline $\begin{array}{l}\text { Skinfold thickness upper } \\
\text { body }(\mathrm{mm})\end{array}$ & $63.4(28.5)$ & 0.38 & $<0.0001$ \\
\hline $\begin{array}{l}\text { Skinfold thickness lower } \\
\text { body }(\mathrm{mm})\end{array}$ & I8.5 (8.1) & 0.23 & 0.0020 \\
\hline $\begin{array}{l}\text { Skinfold thickness sum of all } \\
\text { sites }(\mathrm{mm})\end{array}$ & $82.0(34.0)$ & 0.37 & $<0.0001$ \\
\hline Percent body fat (\%) & I5.I (4.5) & 0.41 & $<0.0001$ \\
\hline Weekly training hours (h) & $13.9(5.0)$ & -0.09 & \\
\hline $\begin{array}{l}\text { Weekly kilometers swimming } \\
(\mathrm{km})\end{array}$ & $6.3(3.1)$ & -0.22 & 0.0030 \\
\hline Weekly hours swimming (h) & $2.6(1.2)$ & -0.15 & 0.0386 \\
\hline Speed during swimming $(\mathrm{km} / \mathrm{h})$ & $2.9(0.6)$ & -0.22 & $<0.0001$ \\
\hline $\begin{array}{l}\text { Weekly kilometers cycling } \\
(\mathrm{km})\end{array}$ & $\begin{array}{l}194.4 \\
(76.6)\end{array}$ & 0.23 & 0.0018 \\
\hline Weekly hours cycling (h) & $7.1(2.5)$ & -0.11 & \\
\hline Speed during cycling (km/h) & $28.4(3.2)$ & -0.29 & $<0.0001$ \\
\hline Weekly kilometers running $(\mathrm{km})$ & $45.0(15.9)$ & -0.21 & 0.0046 \\
\hline Weekly hours running (h) & $4.3(3.0)$ & 0.00 & \\
\hline Speed during running $(\mathrm{km} / \mathrm{h})$ & II.6 (I.4) & -0.39 & $<0.0001$ \\
\hline Personal best time (minutes) & 130.4 & 0.60 & $<0.0001$ \\
\hline in Olympic triathlon $(n=\mid 50)$ & $(44.2)$ & & \\
\hline Personal best time (minutes) & 193.9 & 0.62 & $<0.0001$ \\
\hline in a marathon $(n=149)$ & $(31.9)$ & & \\
\hline
\end{tabular}

Notes: Results are presented as mean and standard deviation for 184 athletes. $P$ value is inserted for significant association. 
coefficient for bivariate analysis with the Ironman race time. Variables showing multicollinearity $(r>0.9)$ were excluded (see Tables 2 and 3). A total of 150 triathletes (81.5\%) had completed at least one Olympic distance triathlon, and 149 $(81.0 \%)$ athletes had finished at least one marathon prior to the Ironman. In the multivariate analysis (see Table 4), both personal best time in an Olympic distance triathlon (see Figure 1) and in a marathon (see Figure 2) were related to Ironman race time. In total, 126 finishers $(68.5 \%)$ had completed both an Olympic distance triathlon and a marathon before the Ironman. The Ironman race time (minutes) might be partially predicted by the following equation $\left(r^{2}=0.65\right.$, standard error of estimate 56.8$)=152.1+1.332 \times($ personal best time in a marathon, minutes $)+1.964 \times$ (personal best time in an Olympic distance triathlon, minutes) for 126 subjects. The effective race time for these 126 subjects was $691.1 \pm 83.3$ minutes, and the predicted race time using the equation with these two predictor variables was $684.9 \pm 74.2$ minutes. The predicted Ironman race time correlated highly significantly with the achieved Ironman race time (see Figure 3). Figure 4 shows the level of agreement using the Bland-Altman method (bias $=-110.4 \pm 110.3$ minutes) between the effective and the predicted race time. The intraclass correlation between effective and predicted Ironman race time was 0.71 .

\section{Discussion}

The aim of this study was to investigate whether age or basic measurements of anthropometry, training, or previous experience were related to an Ironman race time in recreational male triathletes using bivariate and multivariate analysis. Based on the existing literature for triathletes, it was hypothesized that body fat, cycling training volume, and personal best time in an Olympic distance triathlon would be associated with the Ironman race time. In contrast with the study hypothesis, the results showed that, apart from the personal best time in an Olympic distance triathlon, the personal best time in a marathon was also related to Ironman race time after correction for all covariates in multivariate analysis.

The mean age of the subjects in our study was $40.9 \pm 8.4$ years (with 22 years being the age of the youngest participant and 79 years for the oldest participant) and therefore higher than that of $34.2 \pm 8.8$ years for the subjects reported by Gulbin and Gaffney. ${ }^{6}$ However, the mean age in both studies was still below 50 years, which is the age when performance starts to decline in both Olympic distance and Ironman triathletes ${ }^{12,13}$ as well as in marathon and half-marathon runners. ${ }^{14}$ Body fat, as hypothesized, was related to Ironman race time in the present study in bivariate analysis, as has already been shown for Ironman triathletes. ${ }^{3,4}$ However, body fat was no longer a predictor variable when controlled for with all covariates in the multivariate analysis.

The performance in an Olympic distance triathlon seems to be an important predictor variable for Ironman race time. ${ }^{6,7}$ Gulbin and Gaffney found in their retrospective data analysis including 242 male and female Ironman triathletes, when only analyzing training characteristics, that the Ironman race time was predicted by the previous best performance in an Olympic distance triathlon, together with weekly cycling distances and the longest training ride. ${ }^{6}$ In contrast, we found no association with cycling training characteristics. A difference between their investigation and our study was that they did not include anthropometric measurements which might have influenced their multivariate statistical analysis. In addition, we included personal best marathon time as an additional potential predictor variable. Although Gulbin and Gaffney ${ }^{6}$ investigated low-level athletes, as we did, they included both male and female Ironman triathletes. In general, Ironman race time in females is approximately $10 \%{ }^{1}$ to $30 \%{ }^{2}$ slower compared with males, depending on the age of the athletes.

A further difference might also be the selection of subjects. Participants in the present study finished the Ironman triathlon within 11.03 hours, slightly faster than those in the study of Gulbin and Gaffney completing the Ironman race within 11.76 hours. ${ }^{6}$ In addition, our athletes had a higher body weight than theirs $(70.8 \pm 7.1 \mathrm{~kg})$. These differences might be partially explained by the inclusion of female subjects in the Gulbin and Gaffney study. However, those authors were not investigating a potential association between anthropometric characteristics and Ironman race time as we did. ${ }^{6}$ The weekly cycling distance was also included in our data analysis, but this variable was not associated with Ironman race time after multivariate analysis. A reason for these differences might lie in the training of the athletes. The athletes in the study of Gulbin and Gaffney swam $8.8 \mathrm{~km} \pm 4.3 \mathrm{~km}$ per week, cycled $270 \mathrm{~km} \pm 107 \mathrm{~km}$, and ran $58.2 \pm 21.9 \mathrm{~km} .^{6}$ Compared with participants in the present study, the training volume was higher for their athletes. Considering the training speed, the athletes reported on by Gulbin and Gaffney swam at $3.3 \mathrm{~km} /$ hour, cycled at $31.8 \mathrm{~km} /$ hour, and ran at $13.2 \mathrm{~km} /$ hour during training. ${ }^{6}$ These mean values were higher than the values of our participants, although the race time of our subjects was slightly faster than theirs. Presumably the higher volume and higher intensity of cycling training was the reason for the different findings. In addition, the bike course in the Gulbin and Gaffney study (Ironman Lanzarote) was hillier 


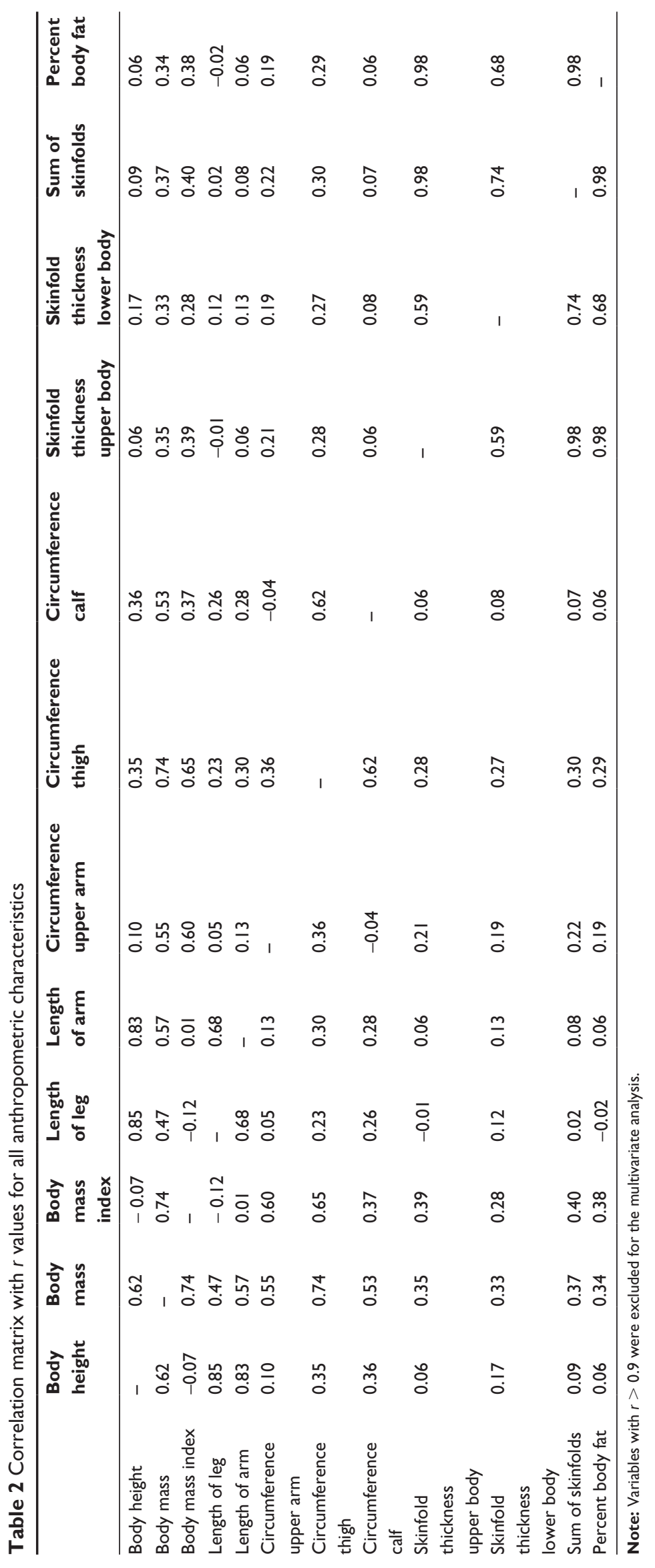




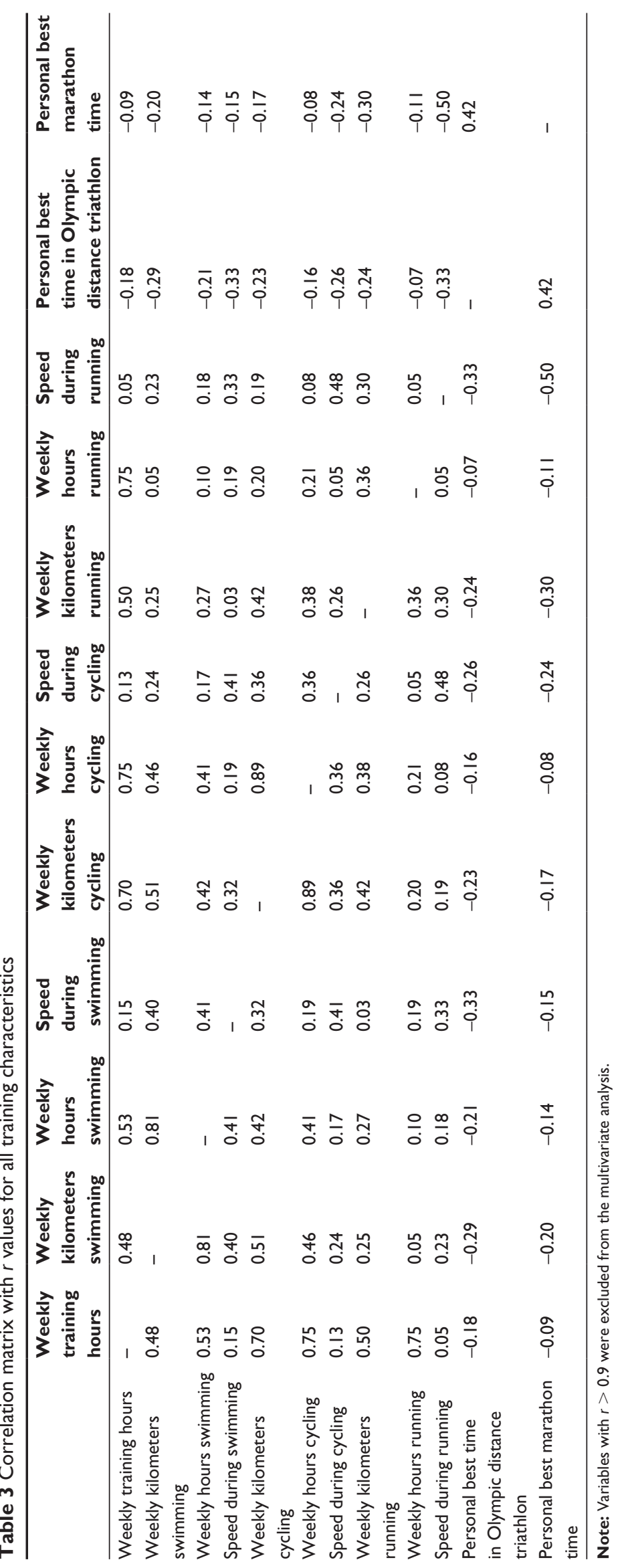


Table 4 Associations between age and anthropometrics, training, and race experience characteristics and Ironman race time using multiple linear regression (126 subjects)

\begin{tabular}{llll}
\hline Variables & $\beta$ & $\begin{array}{l}\text { Standard } \\
\text { error }\end{array}$ & P value \\
\hline Age & 1.96 & 0.61 & 0.19 \\
Body mass & -0.13 & 1.13 & 0.90 \\
Body mass index & 8.39 & 4.46 & 0.06 \\
Circumference of upper arm & 0.19 & 2.67 & 0.94 \\
Circumference of thigh & -2.61 & 2.81 & 0.35 \\
Circumference of calf & 1.76 & 2.45 & 0.47 \\
Percent body fat & 0.16 & 1.37 & 0.90 \\
Weekly kilometers swimming & 1.81 & 3.39 & 0.59 \\
Weekly hours swimming & 1.41 & 7.43 & 0.84 \\
Speed during swimming & -13.9 & 13.54 & 0.30 \\
Weekly kilometers cycling & -0.06 & 0.08 & 0.47 \\
Speed during cycling & 0.58 & 2.23 & 0.79 \\
Weekly kilometers running & 0.39 & 0.40 & 0.32 \\
Speed during running & 2.00 & 4.59 & 0.66 \\
Personal best time in an Olympic & 1.83 & 0.37 & $<0.001$ \\
triathlon & & & \\
Personal best time in a marathon & 1.24 & 0.20 & $<0.001$ \\
\hline
\end{tabular}

compared with that for Ironman Switzerland. ${ }^{6}$ Furthermore, Gulbin and Gaffney had included both male and female athletes in their study. In recent studies investigating both male and female Ironman triathletes, differences in the relationship between both anthropometric and training characteristics with Ironman race time have been described. ${ }^{3-5}$

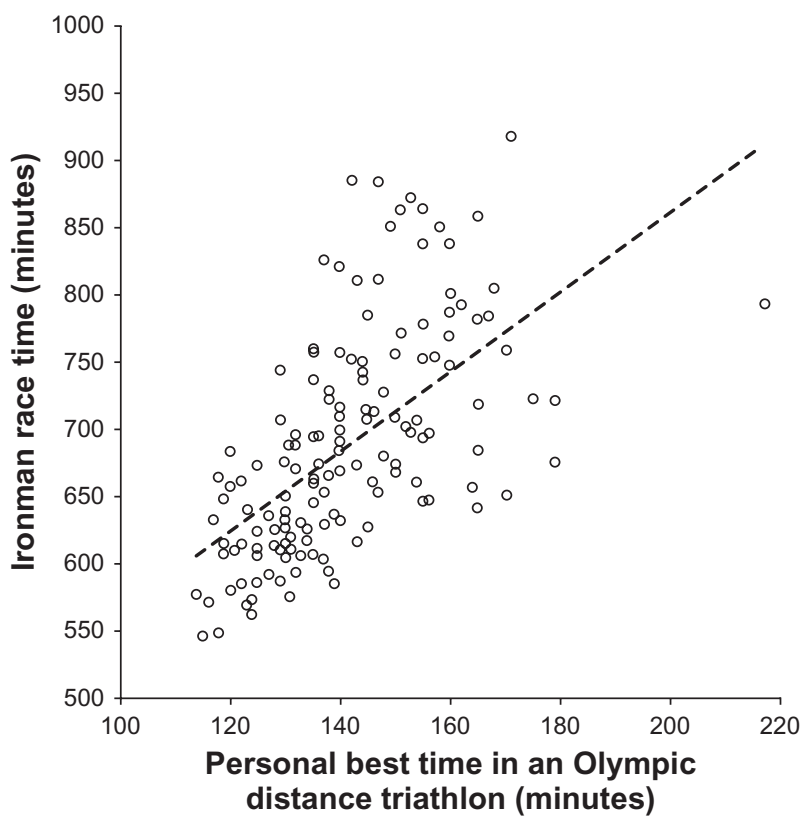

Figure I The personal best time in an Olympic distance triathlon in I 50 subjects was significantly and positively related to the Ironman race time $(r=0.60, P<0.000 \mathrm{I})$. $\beta$, regression coefficient; SE, standard error of the regression coefficient; the coefficient of determination $\left(r^{2}\right)$ of the model was $65 \%$.

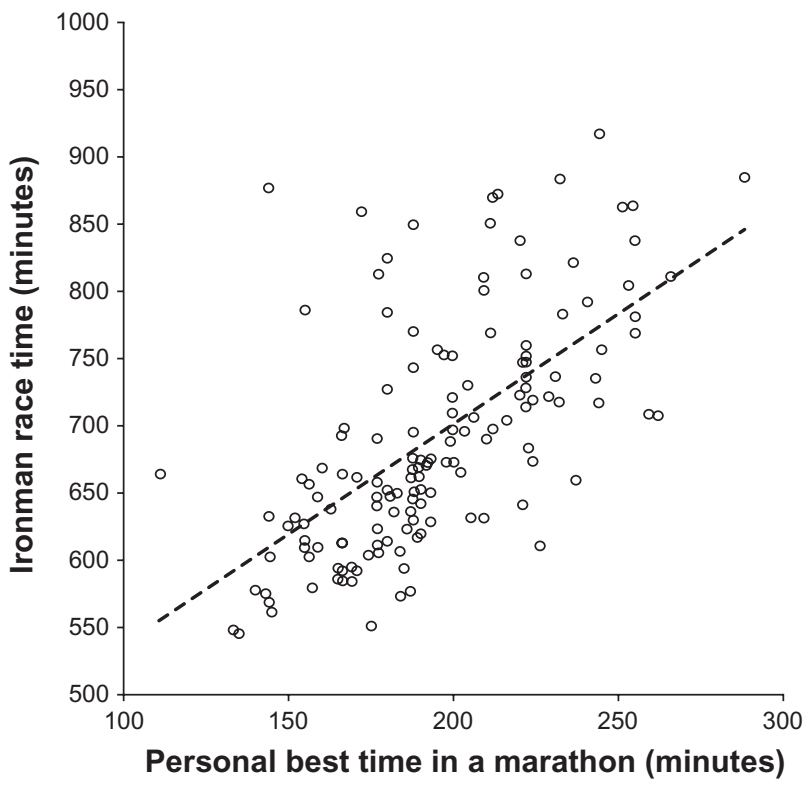

Figure 2 The personal best time in a marathon in 149 subjects was significantly and positively related to the Ironman race time $(r=0.62, P<0.000$ I $)$.

For the present subjects, a significant association of personal best time in marathon running with Ironman race time was found. Running performance might be predictive for an Ironman race performance, as has been shown for Olympic distance triathletes ${ }^{15}$ and Triple Iron ultratriathletes. ${ }^{16}$ Schabort et al described peak treadmill velocity as a predictor variable for Olympic distance triathletes, ${ }^{15}$ and running performance was related to overall race time, but not cycling performance, in Triple Iron ultratriathletes. ${ }^{16}$

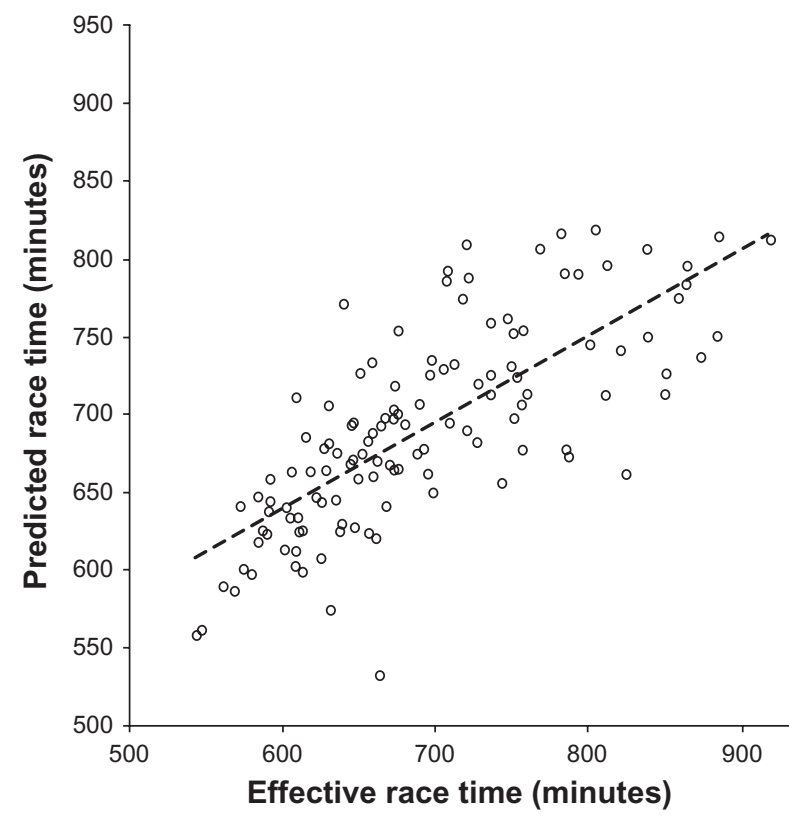

Figure 3 The predicted Ironman race time in 126 subjects correlated significantly to the effective Ironman race time $(r=0.75, P<0.000$ I). 


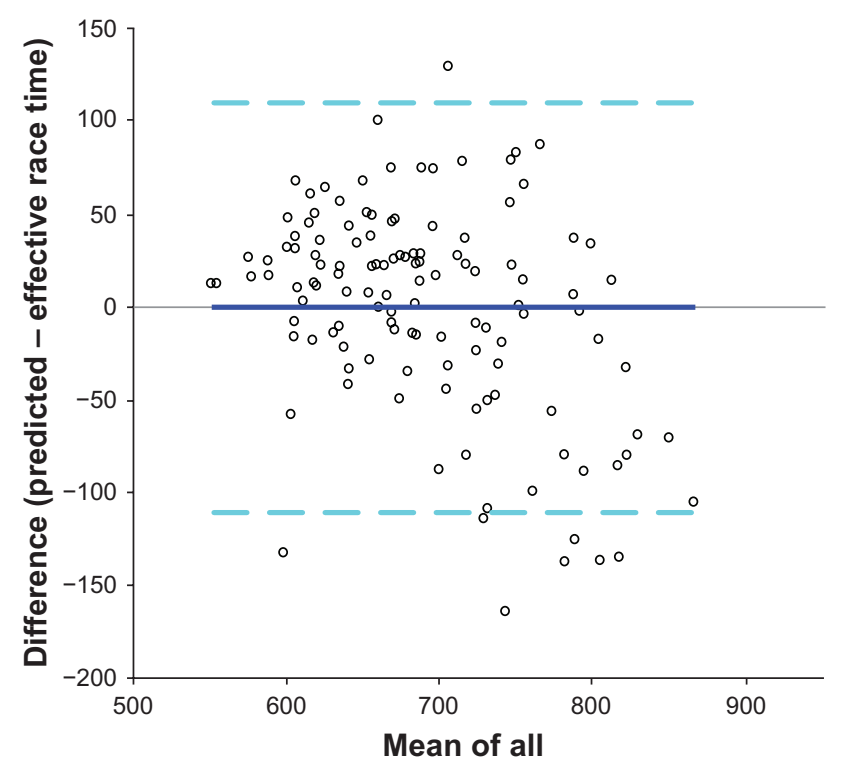

Figure 4 Bland-Altman plots comparing predicted with effective Ironman race time.

The personal best time in a marathon seems also to be a strong predictor variable in ultramarathoners because the personal best time in a marathon was also related to race performance in ultramarathoners. ${ }^{17,18}$ Previous experience seems to be a strong and independent predictor variable for ultraendurance performance. In very recent studies, previous experience has been shown to be the single predictor variable for ultraendurance athletes. ${ }^{19,20}$ However, in the present Ironman triathletes, $34(18.5 \%)$ had not completed a marathon before the Ironman and $35(19 \%)$ had not completed a prerace Olympic distance triathlon. It is obviously possible to finish an Ironman triathlon successfully without previous completion of a marathon or an Olympic distance triathlon.

This study was limited because nutritional intake was not assessed. It is very likely that race nutrition would influence overall race time in Ironman events. ${ }^{21}$ Nutrition should also be considered in further studies. The problem of fluid intake and exercise-associated hyponatremia, in particular, might have an influence on Ironman race time. ${ }^{22,23}$ In addition, environmental factors might influence race performance. ${ }^{24}$ Furthermore, the determination of physiological characteristics, such as maximum oxygen uptake or lactate threshold, would be useful. ${ }^{25}$ Apart from variables of physiology, anthropometry, training, and previous experience, the aspect of motivation might also considerably influence Ironman race outcome. ${ }^{26,27}$ Age might also have an influence on Ironman performance because the present subjects were about 8 years older compared with subjects in the study by Gulbin and Gaffney. ${ }^{6}$ Future studies should investigate whether the percentage of master athletes has increased over the years in Ironman triathlons, such as Ironman Hawaii, as has been shown for marathoners in the New York City Marathon. ${ }^{28}$ Another limitation is that personal best times in marathon and Olympic distance triathlon were achieved on different courses under different environmental conditions. In addition, we must assume that not all athletes accurately recorded their personal best times. We have data on 126 athletes $(68.5 \%)$ who completed both a marathon and an Olympic distance triathlon before the Ironman. This percentage might be the reason that $r^{2}$ of the equation was rather low at 0.65 .

Furthermore, this study was limited to male athletes. Future studies should also investigate female Ironman triathletes. In a small sample of recreational female triathletes, personal best time in a marathon $(r=0.51)$, personal best time in an Olympic distance triathlon $(r=0.70)$, and personal best time in an Ironman triathlon $(r=0.70)$ were significantly and positively related to Ironman race time. Also, personal best time in an Olympic distance triathlon was significantly and positively related to personal best time in an Ironman triathlon $(r=0.63) .{ }^{29}$ Personal best times in both an Olympic distance triathlon and a marathon might also be strong and independent predictor variables for Ironman race time in female triathletes, as has been shown here for male athletes.

\section{Conclusion}

In contrast with previous findings of anthropometric and training characteristics being predictive of Ironman race time, personal best times in both a marathon and an Olympic distance triathlon were strong predictor variables for Ironman race time in recreational male Ironman triathletes. For these recreational male triathletes, Ironman race time might be partially predicted by the following equation: $r^{2}=0.65$ (standard error of estimate $=56.8)=152.1+1.332 \times($ personal best time in a marathon, minutes $)+1.964 \times$ (personal best time in an Olympic distance triathlon, minutes). Athletes, coaches, and dieticians, when planning for an athlete's first event, should focus on gaining prerace experience in both marathon running and finishing Olympic distance triathlons in order to successfully finish an Ironman triathlon. Further studies examining the physiological and psychological characteristics of Ironman triathletes are required to better understand the determinants of Ironman triathlon performance. The inclusion of physiological variables might increase the $r^{2}$ of the equation. 


\section{Acknowledgment}

We thank Mary Miller for her help in translation.

\section{Disclosure}

The authors report no conflicts of interest in this work.

\section{References}

1. Lepers R. Analysis of Hawaii Ironman performances in elite triathletes from1981-2007. Med Sci Sports Exerc. 2008;40:828-834.

2. Lepers R, Maffiuletti N. Age and gender interactions in ultraendurance performance: Insight from triathlon. Med Sci Sports Exerc. 2011;43:134-139.

3. Knechtle B, Wirth A, Baumann B, Knechtle P, Rosemann T, Oliver S. Differential correlations between anthropometry, training volume, and performance in male and female Ironman triathletes. J Strength Cond Res. 2010;24:2785-2793.

4. Knechtle B, Wirth A, Baumann B, Knechtle P, Rosemann T. Personal best time, percent body fat, and training are differently associated with race time for male and female Ironman triathletes. Res Q Exerc Sport. 2010;81:62-68.

5. Knechtle B, Knechtle P, Rosemann T. Upper body skinfold thickness is related to race performance in male Ironman triathletes. Int J Sports Med. 2011;32:20-27.

6. Gulbin JP, Gaffney PT. Ultraendurance triathlon participation: Typical race preparation of lower level triathletes. J Sports Med Phys Fitness. 1999;39:12-15.

7. Knechtle B, Wirth A, Rosemann T. Predictors of race time in male Ironman triathletes: Physical characteristics, training, or prerace experience? Percept Mot Skills. 2010;111:437-446.

8. Becque MD, Katch VL, Moffatt RJ. Time course of skin-plus-fat compression in males and females. Hum Biol. 1986;58:33-42.

9. Ball SD, Altena TS, Swan PD. Comparison of anthropometry to DXA: A new prediction equation for men. Eur J Clin Nutr. 2004;58:1525-1531.

10. Knechtle B, Joleska I, Wirth A, Knechtle P, Rosemann T, Senn O. Intra- and inter-judge reliabilities in measuring the skin-fold thicknesses of ultra runners under field conditions. Percept Mot Skills. 2010;111:105-106.

11. Gatsonis C, Sampson AR. Multiple correlation: Exact power and sample size calculations. Psychol Bull. 1989;106:516-524.

12. Bernard T. Sultana F, Lepers R, Hausswirth C, Brisswalter J. Agerelated decline in Olympic triathlon performance: Effect of locomotion mode. Exp Aging Res. 2010;36:64-78.

13. Lepers R, Sultana F, Thierry B, Hausswirth J, Brisswalter J. Age-related changes in triathlon performances. Int J Sports Med. 2010;31:251-256.
14. Leyk D, Erley O, Ridder D, et al. Age-related changes in marathon and half-marathon performances. Int J Sports Med. 2007;28:513-517.

15. Schabort EJ, Killian SC, St Clair Gibson A, Hawley JA, Noakes TD. Prediction of triathlon race time from laboratory testing in national triathletes. Med Sci Sports Exerc. 2000;32:844-849.

16. Knechtle B, Kohler G. Running performance, not anthropometric factors, is associated with race success in a Triple Iron Triathlon. $\mathrm{Br}$ J Sports Med. 2009;43:437-441.

17. Knechtle B, Knechtle P, Rosemann T, Lepers R. Personal best marathon time and longest training run, not anthropometry, predict performance in recreational 24-hour ultra-runners. $J$ Strength Cond Res. 2011;25:2212-2218.

18. Knechtle B, Wirth A, Zimmermann K, Knechtle P, Kohler G. Personal best marathon performance is associated with performance in a 24-hour run and not anthropometry or training volume. Br J Sports Med. 2009;43:836-839.

19. Knechtle B, Knechtle P, Rosemann T, Senn O. Personal best time and training volume, not anthropometry, is related to race performance in the 'Swiss Bike Masters' mountain bike ultramarathon. J Strength Cond Res. 2011;25:1312-1317.

20. Knechtle B, Knechtle P, Rosemann T, Senn O. Personal best time, not anthropometry or training volume, is associated with total race time in a triple iron triathlon. $J$ Strength Cond Res. 2011;25:1142-1150.

21. Kimber NE, Ross JJ, Mason SL, Speedy DB. Energy balance during an Ironman triathlon in male and female triathletes. Int J Sport Nutr Exerc Metab. 2002;12:47-62.

22. Speedy DB, Noakes TD, Rogers IR, et al. Hyponatremia in ultradistance triathletes. Med Sci Sports Exerc. 1999;31:809-815.

23. Speedy DB, Rogers IR, Noakes TD, et al. Exercise-induced hyponatremia in ultradistance triathletes is caused by inappropriate fluid retention. Clin J Sport Med. 2000;10:272-278.

24. Wegelin JA, Hoffman MD. Variables associated with odds of finishing and finish time in a 161-km ultramarathon. Eur J Appl Physiol. 2011;111:145-153.

25. O’Toole ML, Douglas PS, Hiller WD. Lactate, oxygen uptake, and cycling performance in triathletes. Int J Sports Med. 1989;10:413-418.

26. Parry D, Chinnasamy C, Papadopoulou E, Noakes T, Micklewright D. Cognition and performance: Anxiety, mood and perceived exertion among Ironman triathletes. Br J Sports Med. 2010. [Epub ahead of print.]

27. Stoeber J, Uphill MA, Hotham S. Predicting race performance in triathlon: The role of perfectionism, achievement goals, and personal goal setting. J Sport Exerc Psychol. 2009;31:211-245.

28. Lepers R, Cattagni T. Do older athletes reach limits in their performance during marathon running? Age (Dordr). 2011. doi: 10.1007/s11357011-9271-z.

29. Knechtle B, Wirth A, Rosemann T. Is body fat a predictor variable for race performance in recreational female Ironman triathletes? Med Sport. 2011;15:6-12

\section{Publish your work in this journal}

Open Access Journal of Sports Medicine is an international, peer-reviewed, open access journal publishing original research, reports, reviews and commentaries on all areas of sports medicine. The manuscript management system is completely online and includes a very quick and fair peer-review system.

\section{Dovepress}

Visit http://www.dovepress.com/testimonials.php to read real quotes from published authors. 